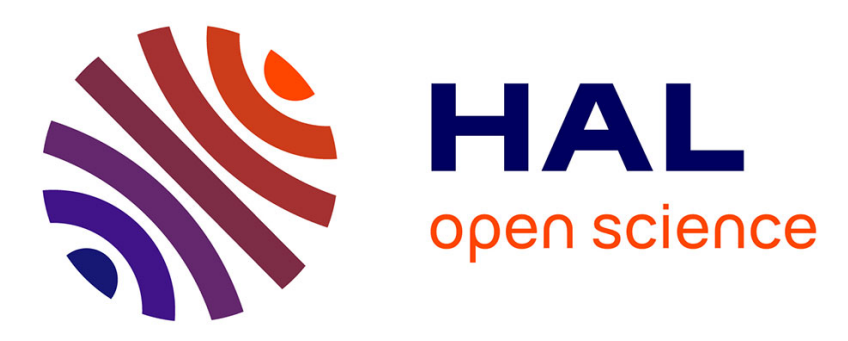

\title{
Vesicular Exocytosis and Microdevices - Microelectrode Arrays
}

Christian Amatore, Jérôme Delacotte, Manon Guille-Collignon, Frédéric

Lemaître

\section{- To cite this version:}

Christian Amatore, Jérôme Delacotte, Manon Guille-Collignon, Frédéric Lemaître. Vesicular Exocytosis and Microdevices - Microelectrode Arrays. Analyst, 2015, 140, pp.3687-3695. 10.1039/C4AN01932F . hal-01154578

\section{HAL Id: hal-01154578 https: / hal.sorbonne-universite.fr/hal-01154578}

Submitted on 22 May 2015

HAL is a multi-disciplinary open access archive for the deposit and dissemination of scientific research documents, whether they are published or not. The documents may come from teaching and research institutions in France or abroad, or from public or private research centers.
L'archive ouverte pluridisciplinaire HAL, est destinée au dépôt et à la diffusion de documents scientifiques de niveau recherche, publiés ou non, émanant des établissements d'enseignement et de recherche français ou étrangers, des laboratoires publics ou privés. 
Minireview for Analyst

\section{Vesicular Exocytosis and Microdevices - Microelectrode Arrays}

Christian Amatore, Jérôme Delacotte, Manon Guille-Collignon, ${ }^{*}$ Frédéric Lemaître ${ }^{*}$

Ecole Normale Supérieure-PSL Research University, Département de Chimie, Sorbonne Universités - UPMC Univ Paris 06, CNRS UMR 8640 PASTEUR, 24, rue Lhomond, 75005 Paris, France.

* Corresponding authors: Dr. C. Amatore, Dr. M. Guille-Collignon, Dr. F. Lemaître Tel : 33-1-4432-3388 ; Fax: 33-1-4432-3863. E-mails: christian.amatore@ens.fr, frederic.lemaitre@ens.fr, manon.guille@ens.fr

Number of figures: 4

Pages : 22 


\begin{abstract}
Among all the analytical techniques able to monitor exocytosis in real time at the single cell level, electrochemistry (particularly amperometry at constant potential) using ultramicroelectrodes has been demonstrated to be an important and convenient tool for more than two decades. Indeed, because the electrochemical sensor is located in the close vicinity of the emitting cell ("artificial synapse" configuration), many data can be gathered from the whole cell activity (secretion frequency) to the individual vesicular release (duration, fluxes or amount of molecules released) with an excellent sensitivity. However, such a single cell analysis and its intrinsic benefits are at the expense of the spatial resolution or/and the number of experiments. The quite recent development of microdevices/microsystems (and mainly the microelectrode arrays; MEAs) offers in some way a complementary approach either by combining spectroscopies-microscopies or by implementing a multianalysis. Such developments are described and discussed in the present review over the 20052014 period.
\end{abstract}

Keywords : exocytosis; amperometry; ultramicroelectrodes; microsystems; arrays 


\section{Introduction}

\subsection{What is vesicular exocytosis?}

Vesicular exocytosis is an essential biological mechanism involved in the intercellular communication and particularly in the case of the chemical synapse transmission occurring in the neural communication. In this respect, messengers or effectors (peptides, proteins, hormones...) will exit the emitting cell, not by directly crossing the plasma membrane, but by the mean of secreting vesicles that fuse with the cell membrane and subsequently release their content in the extracellular medium. ${ }^{1}$ Several steps can overall describe the mechanism of vesicular exocytosis (Figure 1A). Firstly, an intracellular $\mathrm{Ca}^{2+}$ increase is triggered with the help of an appropriate stimulation. Available secretory vesicles thus move from the cell cytoplasm to the cell membrane at which they dock by the mean of protein assemblies named SNAREs (soluble N-ethylmaleimide sensitive fusion protein attachment receptors). Such SNAREs complexes notably contribute to overcome the electrostatic repulsions between vesicular and cell membranes. In others words, they make easier the interactions between the membranes and the subsequent formation of a nanometric fusion pore through which the release of the vesicular content towards the extracellular medium can occur. It has to be emphasized that another step can take place according to the cell model or/and the experimental conditions, i.e, an expansion of the pore and a more massive release of the vesicular content.

\subsection{Real time detection of exocytosis at the single cell level}

Due to the steps described above that involve interactions between many vesicles and the cell membrane, analytical methods for the investigation of exocytosis needs to be able to both investigate the release at the single cell and individual vesicular levels in real time. In this way, three analytical methods have been implemented in the past twenty years. First of all, fluorescence microscopy mainly relies on fluorescent vesicular markers in order to observe the intravesicular medium or the vesicles membranes. Therefore, individual secretory vesicles can be visualised before (motion within the cytoplasm) and during the exocytotic release (location at the cell membrane). ${ }^{2,3}$ More particularly, fluorescence measurement involving an evanescent wave field (Total Internal Reflection Fluorescence Microscopy; TIRFM) were evidenced to limit cell damages and increase the signal to noise ratio by 
only considering the close vicinity of the cell membrane. Secondly, electrophysiological measurements involving the "patch-clamp" techniques can be also considered. In this case, by sealing a "patch" of the cell membrane with a glass micropipette, impedance analyses can give access to realtime capacitance/conductivity measurements, i.e., the monitoring of the cell membrane surface due to each vesicle fusion and the fusion pore formation respectively. ${ }^{4,5}$ Finally, electrochemical techniques also contributed to the investigations of exocytosis at the single cell level, particularly amperometry using ultramicroelectrodes (UMEs). Briefly, a micrometric carbon fiber electrode (UME) is positioned at the top and near the emitting cell (Figure 1B). By applying an appropriate constant potential value, the molecules released by exocytosis (mainly catecholamines) can be oxidised at the electrode surface, thus leading to a spike of current for each individual vesicular release by exocytosis. As a consequence, the cell release at the cell apex will correspond to a succession of amperometric spikes whose detailed analysis will give important data related to the whole cell activity (spikes frequency) and/or the dynamics and the amount of biomessengers released for each exocytotic event (Figure 1C). It has to be emphasized that such an experimental configuration mimics the chemical synapse, the UME corresponding to the receiving neuron. This is why it is sometimes named as the "artificial synapse" configuration.

\subsection{Why microsystems for the electrochemical detection of exocytosis?}

In the two last decades, analytical properties of UMEs (enhanced signal-to-noise ratio, fast and appropriate response time...) combined to the "artificial synapse" configuration significantly contributed to the understanding of the exocytotic mechanism (physico-chemical vs biological control, partial vs full fusion....) ${ }^{6}$ Nevertheless, the electrochemical method itself suffers from certain disadvantages. The first one concerns the single cell analysis that requires many experiments to overcome the cell variability and thus reach a relevant statistical treatment. The second one is related to the fact that the electroanalytical recording only detects "one half of exocytotic event" due to the location of the UME in the extracellular medium above the cell.

Due to recent advances in microfabrication procedures, developments of microsystems and microdevices greatly contributed to new analytical strategies notability related to miniaturization ("lab 
on a chip"), involving small solution volumes or especially allowing parallel measurements. Therefore, microsystems and microdevices should solve many analytical issues where electrochemical detection of exocytosis does not make an exception in that regard that microelectrode arrays (MEAs) and transparent microsystems particularly fit with the two drawbacks mentioned above.

In this review, we reported the main results obtained with amperometric detection of exocytosis involving microsystems-microdevices over the 2005-2014 period. We will particularly consider the most informative examples related on the one hand to combinatory analysis at two scales (cell population and single cell) and on the other hand to transparent materials for the coupling with intracellular fluorescence techniques. Comparisons with the single carbon fiber electrode configuration will be discussed in the conclusion.

\section{Microsystems for the electrochemical detection of exocytosis: from cell populations} analyses to transparent electrodes.

Microsystems and microdevices devoted to the real time electrochemical monitoring of vesicular exocytosis are tremendous. Indeed, they can be classified in many different ways due to their versatility and potential use in different issues. Therefore, we chose herein to classify them as a function of their main application which partially governs their structure and geometry: combinatory analysis (on entire cell population or on cell population in which single cells can be separately analyzed) or coupling of analytical techniques on transparent microarrays.

\subsection{Analyses at the cell population scale}

As mentioned above, the single cell analysis performed by using a UME requires numerous independent experiments and more particularly if different experimental conditions (extracellular medium composition, membrane modifications...) are compared. As a consequence, microelectrodes arrays (MEAs) seem to be an appropriate way to accumulate experiments on the same device, i.e. to perform a combinatory analysis with a cell population (Figure 2). Before describing some MEAs, it has to be emphasized that from an electroanalytical point of view, using UME arrays is considered as an improvement of the sensitivity in terms of the signal to noise ratio. Indeed, provided that the inter- 
electrode distances are sufficiently low, the diffusion layers of each electrode could merge, thus corresponding to a whole diffusion layer that leads to an increase of the faradic current (the signal) while not changing the capacitive current (the noise). ${ }^{7}$ However, this only applies for homogenous solutions and thus is not relevant if considering electrochemical measurements of exocytosis when the cells adhere to the MEA.

Firstly, the easiest strategy was proposed by Cui et al. eight years ago by the mean of a biochip involving an array of gold disk ultramicroelectrodes. ${ }^{8,9}$ The array is globally disposed over ca. $1 \mathrm{~mm}^{2}$ and includes 25 UMEs (diameters from 10 to $90 \mu \mathrm{m}$ ) with inter-electrode distance of $250 \mu \mathrm{m}$. The MEAs can be carpeted by populations of PC12 or MN9D cells and the neurotransmitters release of the entire cell population can be electrochemically recorded after an appropriate stimulation. Taking benefits of their simplicity such MEAs correspond to potential platforms able to perform drug screening (L-DOPA, reserpine, nomifensine). Comparable investigations were achieved with 12 sets of MEAs (doped overoxidized polypyrrole gold electrodes) on a population of differentiated PC12 cells. ${ }^{10}$ Nevertheless, in both cases, the single cell resolution is totally lost and the response will obviously depend on the cell coverage, thus leading to lose the individual vesicle resolution. ${ }^{11}$

Furthermore, while appropriate treatments for promoting cell adhesion were achieved (physisorbed laminin, collagen), no control of the cells location (on the electrode surface or on the insulating material) can be done. In the same way, another simple microdevice has been reported by Wolfrum et coll. that includes a screen-printed carbon paste millimetric electrode covered by a thin PDMS (polydimethylsiloxane) film. ${ }^{12}$ By poking a hole with a needle through the PDMS layer, a carbon micrometric surface is exposed allowing a PC12 cell population dropping on the UME and investigations by electrochemistry about its release . More sophisticated MEAs can be considered in which the array is inserted within a microfluidic channel, as reported by Gao et al. who described a microdevice with 16 DLC:N (nitrogen-doped diamond-like carbon) ultramicroelectrodes (30 $\mu \mathrm{m}$ x 40 $\mu \mathrm{m}) .{ }^{13}$ Small groups of chromaffin cells can thus be located on each electrode surface.

The positioning of cells on the electrode surface has been notably addressed by the group of K. D. Gillis. As an example, a microchip device has been implemented with microfluidic traps which automatically enforce individual chromaffin cells or small groups of chromaffin cells to be located on 
platinum ultramicroelectrodes. ${ }^{14}$ The electrochemical recording has been readily achieved, thus extracted data contributed to the issues dealing with the release dynamics at the top and bottom of the cell. A similar strategy was reported by Ges et al. with platinum electrodes covered by iridium oxide films. ${ }^{15}$ In both cases, it cannot be excluded that the mechanical or hydrodynamic stress applied to cells may alter the cell response. This is probably why devices with two connected PDMS channels were recently reported within the same group. In this way, small populations of chromaffin cells can be moved and positioned on indium tin oxide square microelectrodes $(10 \mu \mathrm{m} \times 10 \mu \mathrm{m})$ by using a moderate hydraulic pressure. ${ }^{16}$ The consistency of the electrochemical results with established data on chromaffin cells suggests that this soft trapping method is adapted and did not alter the cell responses. Indeed here the cells are only transported by controlling the solution heights between the inlet and outlet reservoirs. It has to be emphasized that an ingenious strategy for trapping the cells has been recently published by Baudenbacher et coll. ${ }^{17}$ By considering a MEAs with interdigitated platinum band electrodes (50 $\mu \mathrm{m}$ width) and PDMS channels, U-shaped cell traps were added to the microsystem in order to stop and position small groups of chromaffin cells at the UME surfaces. Electrochemical recordings of exocytotic release were achieved with a good sensitivity with different secretagogues (PACAP, $\mathrm{KCl}$, carbachol), thus giving hope to use this device for screening drug effects. Another way to trap the cells on the MEA is to use a microchannel (crossed by eight independent gold working electrodes) in which the cells are injected but with a reduction of the microchannel size when crossing the electrodes. ${ }^{18}$ In this way, clusters of PC12 cells and single cell can be isolated, thus raising once again the question of the effects of the cell compression and shear stress on its exocytotic release.

Some microdevices can be used for others issues than achieving an analysis of a cell population. For instance, A.G. Ewing and coll. reported a microdevice prone to achieve analyses by electrochemical cytometry. ${ }^{19}$ Briefly, vesicles can be isolated from cells suspension after centrifugation and subsequently inserted in the microsystem. This last allows vesicles separation, lysis and the final electrochemical monitoring of their content at a carbon fiber ultramicroelectrode surface. The results were used to contribute to the debate related to the full/partial fusion during exocytosis 


\subsection{Analyses at the single cell or subcellular level}

As mentioned in the introduction, though amperometry exhibits a high sensitivity, UMEs do not allow spatial resolution at the sub-cellular scale. For last years, MEAs have thus been used to circumvent this lack of spatial resolution. As shown in Figure 3, a MEA consists in a set of electrodes with typical size of a few microns each. If individually addressable, these electrodes can be used to monitor exocytosis at the subcellular scale. Several MEAs' implementations were recently reported in literature, for example by exploring different approaches for electrode fabrication and positioning. New materials were also proposed to improve electrode properties.

In this way, Zhang et al. have built a MEA consisting of an array of 7 carbon fiber UMEs with $2.5 \mu \mathrm{m}$ size. ${ }^{20}$ The array, obtained from fibers embedded in glass capillaries and melt altogether under pulling, was 10-20 $\mu \mathrm{m}$ in diameter. This MEA located at the end of a micropipette-like glass rod allowed to detect neurotransmitters release by amperometry from the apex of the cell. The MEA was characterized through SEM (Scanning Electron Microscopy), cyclic voltammetry and numerical simulation. The validation of the device was carried out through the detection of neurotransmitters released by PC12 cells. The secretion heterogeneity(hot and cold spots) was found to be consistent with data reported in the literature. More recently, the number of electrodes was increased up to 15 by Lin et al. ${ }^{21}$ The carbon fiber microelectrodes array was obtained by carbon deposition in glass capillaries leading to a $10-50 \mu \mathrm{m}$ size array. The device was validated through detection of hot and cold spots on PC12 cells at their apex.

In the former, the artificial synapse configuration was achieved by locating the MEA at the cell apex. Alternatively, the artificial synapse can be obtained at the bottom, i.e., when cells are cultured or deposited on the substrate in which the electrodes are embedded. In 2005, Hafez et al. already reported on an array of 4 square shaped electrodes $(3 \mu \mathrm{m})$ located at the corners of a $10 \mu \mathrm{m}$ square. These platinium electrodes, obtained by metal deposition on a glass plate, allowed spatially and temporally resolved electrochemical detection of release by chromaffin cells that are deposited on the array thanks to micropipette manipulation. ${ }^{22}$ Simultaneous fluorescence imaging was performed in order to validate the position of release sites firstly determined by amperometry. Similar spatial mapping can be also achieved by using boron-doped diamond UMEs. In that way, from four to nine UMEs can be 
included within a micrometric well in which a single cell can be positioned and its exocytotic release be electrochemically investigated. ${ }^{23,}{ }^{24}$ Later on, Wang et al. extended the number of electrodes up to 36 microfabricated platinum UMEs on a glass coverslip. ${ }^{25}$ The amperometric response allowed characterizing the spatial release of dopamine from PC12 cells. These cells had been cultured on top of the electrodes array that had been coated with collagen IV for adhesion. Furthermore, the device was also used to investigate the release of dopamine from cell clusters that exhibited the same electrochemical response than single cells. The configuration of the MEA was then modified in order to trap single cells on the top of arrays lying at the bottom of individual wells. ${ }^{26}$ This design was validated through the amperometric response on PC12 cells. Here again, the detection of hot spots and cold spots was used as a marker.

Microfabricated platinum or diamond electrodes array were not the only alternative to carbon fiber microelectrodes array proposed in the last decade. In that way, some advances in electrodes arrays were carried out not to enhance the spatial resolution of the electrochemical tool but also to consider a single cell analysis with new electrode materials like conducting polymers. ${ }^{27}$ Furthermore, it was shown that single wall carbon nanotubes (CNT) can be modified through functionnalization with biosugars (eg. glucosamine, glucose or mannose) in order to become biocompatible. Exocytotic release at PC12 cell could be detected by amperometry by Sudibya and collaborators, using devices involving electrode arrays based on such CNT networks. ${ }^{28}$ Sensors based on CNTs ITO modified electrodes developed by Shi et al. showed an enhanced sensitivity (3 orders of magnitude) compared to usual ITO electrodes. ${ }^{29}$ In addition, the transparency of the electrode is promising for simultaneous electrochemical and optical analysis (see part 2.3.).

Beyond the amperometric detection of exocytotic release, some efforts have also been devoted to develop sensors operating in voltammetry as well. ${ }^{23,30,31}$

\subsection{Analyses at the single cell level within a cell population}

Several MEAs have been developped to investigate a cell population with the ability to position a single cell at each ultramicroelectrode surface. This is particularly the case of two MEAs reported by the group of K. D. Gillis. ${ }^{32,}{ }^{33}$ In this way, selective surface treatments were performed within the 
MEA. The UMEs surfaces are located at the bottom of wells (10-20 $\mu \mathrm{m}$ diameter) that ensures that only one cell can be placed on the electrode. Furthermore, the electrode surfaces are cytophilic due to their intrinsic cell affinity (nitrogen-doped diamond-like carbon) or thanks to a treatment that promotes cell adhesion (poly-L-Lysine for ITO electrodes). Conversely, the insulating part of the array is cytophobic due to its poor cell affinity (Teflon AF) or after an appropriate treatment (poly(ethylene glycol)). Individual or multi-electrochemical recordings can be potentially considered. It has to be emphasized that the questions envisioned for the mechanical trap of cells can be asked in the case of a cytophobic environment.

Additional and recent developments increased the relevance of such cell population-single cell microsystems. Indeed, during the last decades only one potentiostat was typically involved during the electrochemical investigation. It means that the use of a MEA will enforce recording in the same acquisition all the electrodes signals without any spatial resolution or monitoring the release at only one electrode of the array. However, recent developments (multiplexing, multichannels potentiostats) allows one to record simultaneously and independently the electrochemical responses of all the single electrodes of the MEAs. ${ }^{34}$ As a first example, one can consider the MEA reported by Huang and coll. for which an array of independent platinum UMEs $(6 \times 6 ; 25 \mu \mathrm{m}$ diameter $)$ includes a cell culture chamber. ${ }^{35}$ Beyond its ability to perform cell culture within the MEA (due to a perfusion system), it allows one to electrochemically monitor several independent and parallel single PC12 cell releases. Similar electrochemical monitoring of exocytosis can be achieved with an array of four boron doped nanocrystalline diamond electrodes isolated in $16 \mu \mathrm{m}$ diameter wells. ${ }^{24}$ Four simultaneous amperometric traces can be recorded simultaneously, each one being related to a single chromaffin cell.

Finally, two recent MEAs combining parallel single cell analyses within a cell population were recently reported. ${ }^{25,} 36$ Such MEA chips globally contained numerous simultaneously addressable ultramicroelectrodes (from 16 to 64) with cellular and even subcellular electrode dimensions (from 3 and $12 \mu \mathrm{m})$. High-throughput real time measurements on PC12 cells were here achieved and applied to pharmacological screening (nomifensine, reserpine, L-DOPA...). 


\subsection{Transparent microdevices: combining analytical techniques}

Combining analytical techniques to shine more light on exocytotic process generally implies to use optical techniques with electrochemical ones (Figure 4). This is particularly the case for fluorescence techniques. Indeed, secretion vesicles can be stained with different fluorescent probes, in order to make visible vesicle motion, docking, fusion of vesicles seen in fluorescence microscopy. Therefore, electrochemistry and fluorescence correspond to complementary tools for investigating exocytosis at the single cell level. Indeed they potentially allow one to monitor a whole exocytotic event, from the location of a given intracellular vesicle to its extracellular release. Furthermore, by considering the spatial mapping of the cell surface, fluorescence microscopy is more advantageous than subcellular scale MEAs (see part 2.2) due to a better spatial resolution (120 nm at most). This is the mean reason why microchips or MEAs have been blossomed for 10 years to combine the traditional electrochemical and fluorescence recordings for exocytosis.

\subsubsection{Microdevices for TIRF-amperometry combination}

In order to perform such combined measurements, microfabricated devices obviously have to rely on electrode materials with excellent electrochemical (conductivity) and optical (transparency) properties. ${ }^{37}$ Additionally, the coupled detection has to occur on the same cell area. This was well illustrated by attempts to perform fluorescence and electrochemical recordings with a non transparent platinum microelectrode at the bottom of SH-SY5Y neuroblastoma cells. ${ }^{38}$ In this work, napthalene2,3-dicarboxaldehyde (NDA) was used to mark the cells. Unfortunately, fluorescent recordings showed a bad signal-to-noise resolution and in order to gain a better contrast, subtraction of background fluorescence images was achieved with MatLab software. Furthermore, due to the non transparent electrode, coupled events were not acquired at the same area of the cell. Electrochemical monitoring was thus performed on the platinum microelectrode surface (bottom of the cells) when fluorescence imaging is performed on the upper surface of the cells. The authors found that some amperometric spikes can be roughly correlated together with a quite large temporal precision of few seconds which is consistent with the experimental configuration considered here. 
Moreover, usual epifluorescence techniques can be hardly envisioned for such a purpose. This is why the optical technique usually employed for exocytosis monitoring is rather TIRFM (for "total internal reflection fluorescence microscopy") due to its excellent bioanalytical properties compare to epifluorescence (temporal and spatial resolution, low cell damages, no photobleaching) or other wide field techniques. It has to be emphasized that TIRFM is performed in the cell stratum adherent on the coverslip (on the first few hundreds of nm of cell adherent to the surface). Briefly, an evanescent wave is created by the total internal reflection of a laser beam at the interface cell/coverslip. This wave is then able to elicit the fluorescence of fluorophores of vesicles beforehand marked in their membrane or within them. It also has the advantage to offer a high signal-to-noise ratio in the x-y plane. A first step in the coupling of fluorescent techniques and electrochemical ones was achieved in 2006. On the one hand, the secretion of a chromaffin cell was shown to be detectable on a basic ITO electrode surface. On the other hand, acridine orange was loaded in the cells and its fluorescence within them was monitored by classical fluorescence. ${ }^{39}$ But combining fluorescence (TIRFM) and electrochemistry is a hard task mainly because of the various and opposite constraints of both techniques. This was achieved by Meunier et al. who modified the properties of their substrate (a transparent and conducting $150 \mathrm{~nm}$ thickness ITO band UME) with a delimited surface area able to perform fluorescence and electrochemical detections at the cell bottom while preventing capacitive interferences. ${ }^{40}$ Beyond the analytical requirements described above, the considered cell model for the coupling is an important issue. Indeed, secretory vesicles have to include a fluorescent dye and an electroactive neurobiomolecule. Moreover, its exocytotic activity should correspond to a relatively low frequency of secretion in order to facilitate the assignment of the optical and amperometrical twins signals. In this work, a stable clone from enterochromaffin BON cells (named BC21) was considered because it expresses a fluorescent protein (GFP, green fluorescent protein) while releasing an electroactive neurotransmitter (serotonin loaded $24-48 \mathrm{~h}$ prior to experiments). ${ }^{41}$ After data treatment, only $30 \%$ of the amperometric spikes obtained clearly corresponded to simultaneous optical and amperometrical detection of exocytotic events. Furthermore, other ITO microdevices (spiral wells...) can be fabricated in order to optimize the intrinsic qualities (signal-to-noise ratio, probability to find an isolated cell on the electrode surface...) of the chips for coupling detection. ${ }^{42}$ 
However, TIRFM-electrochemistry combination for exocytosis recordings is not limited to ITO material based arrays. Thus, such a coupling has been successively achieved at single cell level by using microsystems with a well ( $8 \mu \mathrm{m}$ diameter) delimited by a photoresist in which the working electrode is positioned or with a micrometric squared zone $(\sim 15 \mu \mathrm{m}$ side $)$ with four electrodes inside. ${ }^{43}$ The question of the ideal transparent and conducting electrode material remains an important issue and comparisons considering various conducting/transparent materials have been brought. ITO but also thin gold or nitrogen-doped diamond-like carbon materials are investigated. The authors showed a slight loose of sensibility on ITO compared to the two other materials besides the fact that each material has, as expected, advantages and drawbacks (transparency for ITO but not for Au, good electrochemical detection for Au and DLC:N).

\subsubsection{Microdevices for fluorimetry-amperometry combination}

The fluorescence-electrochemistry coupling does not necessarily involve TIRFM as a fluorescence technique. For instance, fluorimetric measurements (with the use of fluorescent calcium indicators) can be also considered as a tool to measure the intracellular $\mathrm{Ca}^{2+}$ concentration in the early steps of exocytosis. In that way, the group of K. Gillis reported on some microdevices based on transparent substrates like ITO or diamond like carbon doped nitrogen ITO (DLC:N). As a first example, a microsystem with transparent ITO UMEs was developed with the particularity of using microfluidic channels (100 $\mu \mathrm{m}$ wide by $100 \mu \mathrm{m}$ deep) in which electrodes were positioned. Chromaffin cells were loaded and adhered to the ITO electrodes treated with polylysine to facilitate adhesion. Stimulation is performed via microfluidic network with a "high- $\mathrm{K}^{+}$solution" and monitoring of catecholamines oxidation is realized on the ITO electrodes beneath the cells. ${ }^{44}$ Such a device was extended to an "amperometry and photometry chip system" by coupling amperometrical detection on ITO with photolysis of caged $\mathrm{Ca}^{2+}$ on transparent electrodes. Photorelease of caged $\mathrm{Ca}^{2+}$ in cells was achieved by fluorescence monitorings using caged $\mathrm{Ca}^{2+}$ and $\mathrm{Ca}^{2+}$ indicator dye fura-4F. This ITO microsystem was suitable for exocytosis monitoring because observation of a burst of amperometric spikes was concomitant with fast elevation of internal $\mathrm{Ca}^{2+}$. This combination is important because it permits, on the ITO microelectrode array, an accurate control of the calcium secretagogue concomitantly with 
amperometrical recording on few cells. It can allow in the future for example drugs screening or studies with GFP proteins reporter of gene expression during exocytosis. ${ }^{45}$

\section{Conclusion}

This mini-review summarized examples of works devoted to the electrochemical detection of exocytosis by involving microsystems and microdevices. While a classification still remains arbitrary, two main applications are concerned: scale of analysis (multi-analysis at the cell population, single cell or subcellular levels) and coupling with optical techniques. Beyond all these applications, it raises the difficult question of the ideal microdevice for investigating exocytosis at the single cell level. Obviously, a given microsystem depends on the bioanalytical applications for which it is implemented, thus leading to hardly describe the perfect device. Nevertheless, an unified microdevice could include over hundred independent and transparent micrometric electrodes at which each single cell could be easily located. The electrode material would be not to thick $(<100 \mathrm{~nm})$ with a good transparency and conductivity and the surface treatment should help the cell adhesion without altering the optical and electrochemical properties and with preservation of a good temporal resolution $(<10$ ms). Concerning the mapping of the single cell release by the mean of a MEA with numerous ultramicroelectrodes under the cell membrane, the current spatial resolution of the best MEA is indeed limited by the size of each UME $(\sim 3 \mu \mathrm{m})$ if compared to the mean cell dimensions (diameter $\sim 10 \mu \mathrm{m}$ ). Such a strategy will be efficient only with an ideal MEA for which UMEs size will decrease to submicrometric dimensions.

Examples of potentially versatile devices can be mentioned. The MEA mentioned above (see part 2.3.) with hydrophobic/cytophilic areas (transparent microelectrodes in DLC:N/ITO) could be also considered for a future combination with fluorescence..$^{33}$ It is also the case of the planar boron-doped NCD (nanocrytalline diamond) array with four transparent detecting ultramicroelectrodes $(20 \mu \mathrm{m}$ diameter) initially implemented for the single cell mapping but potentially able, thanks to the transparency, to be employed for fluorescence detection. ${ }^{46}$

However, this is probably because all these criteria are not totally fulfilled together that the microdevices described here, while corresponding to promising strategies, do not rule out to date the 
"artificial synapse" configuration involving the carbon fiber UME at the top of a single cell. However, even if it was the case, microsystems themselves may still have shortcomings. As an example, they mainly involve an electrochemical detection at the cell bottom, thus meaning that the surface at which the cells adhere is also the electrode surface. Due to the inevitable micrometric dimensions of the working electrode, the control of the location of each single cell at the electrode surface requires many potentially invasive complexities (surface treatment, cell displacements...). By comparison, the configuration with the carbon fiber UME remains particularly easier since the UME is moved with micromanipulators towards the investigated cell. It thus suggests that microsystems-microdevices will be surely an important and complementary tool by extending the scope of application of the historical configuration but without totally excluding it.

\section{Acknowledgments}

This work has been supported by CNRS (UMR 8640, FR2702), Ecole Normale Supérieure, French Ministry of Research, Université Pierre \& Marie Curie Paris 06. 
Figure 1.

A)

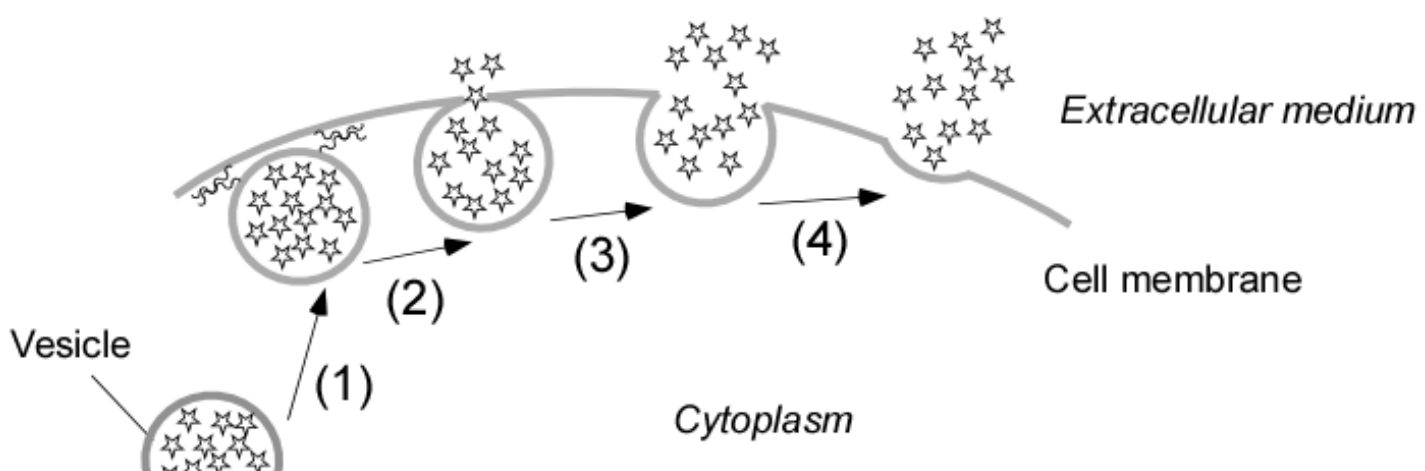

B)

Neurotransmitters

C)

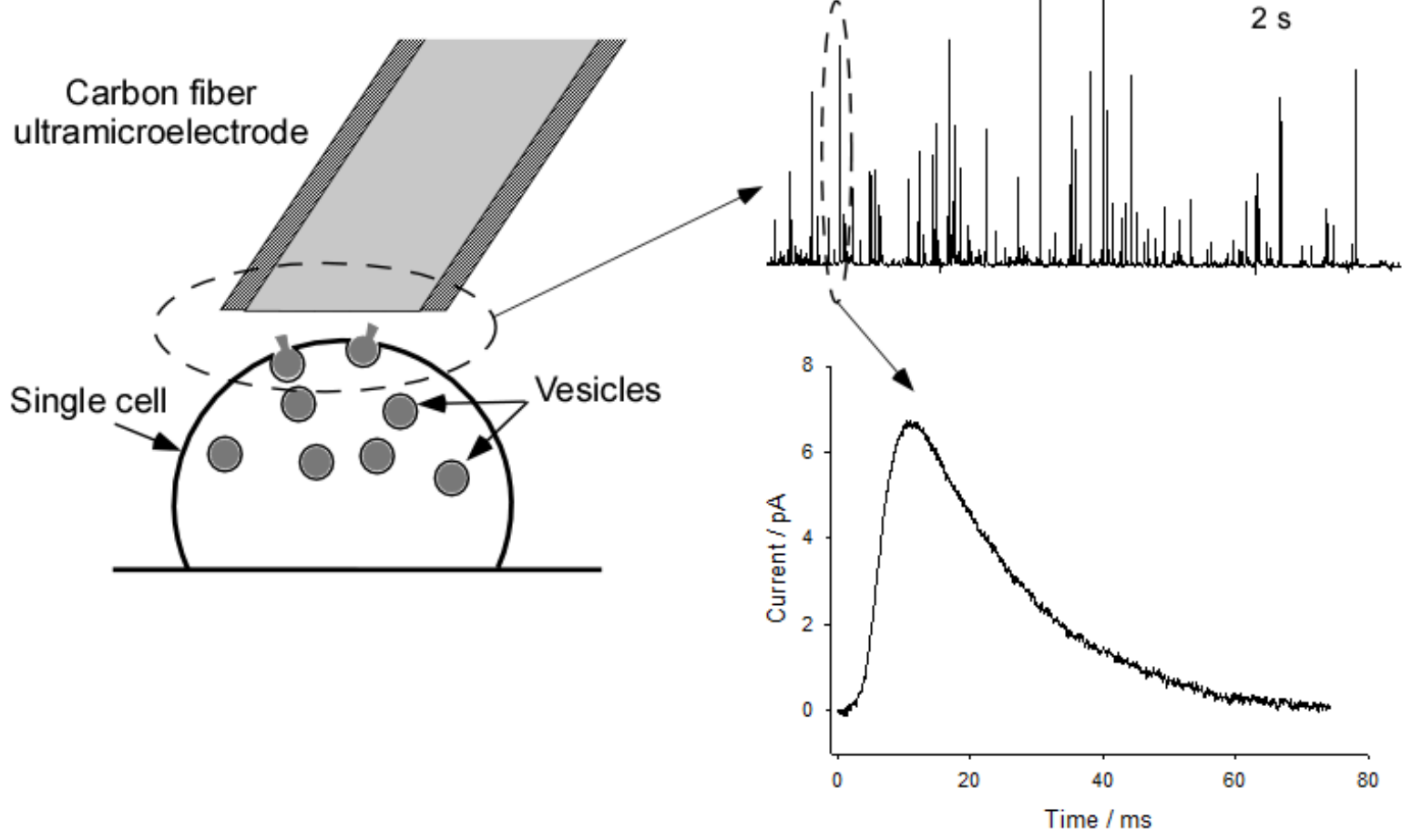


Figure 2.

A)

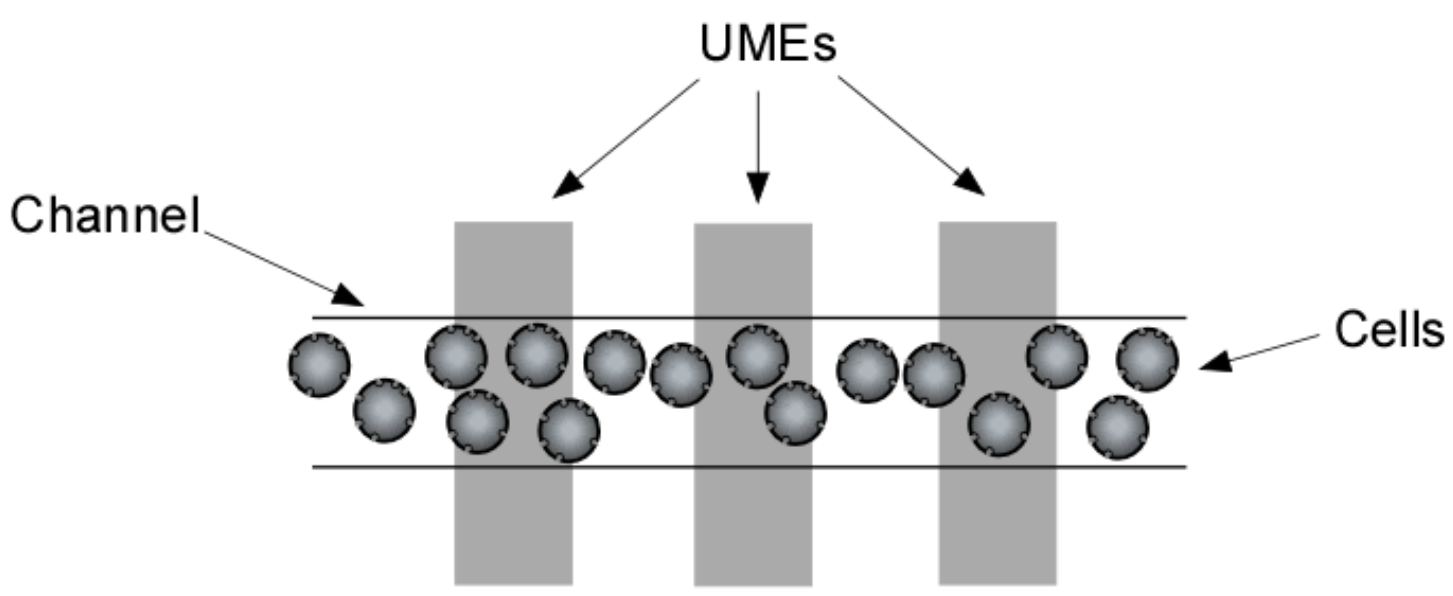

B)

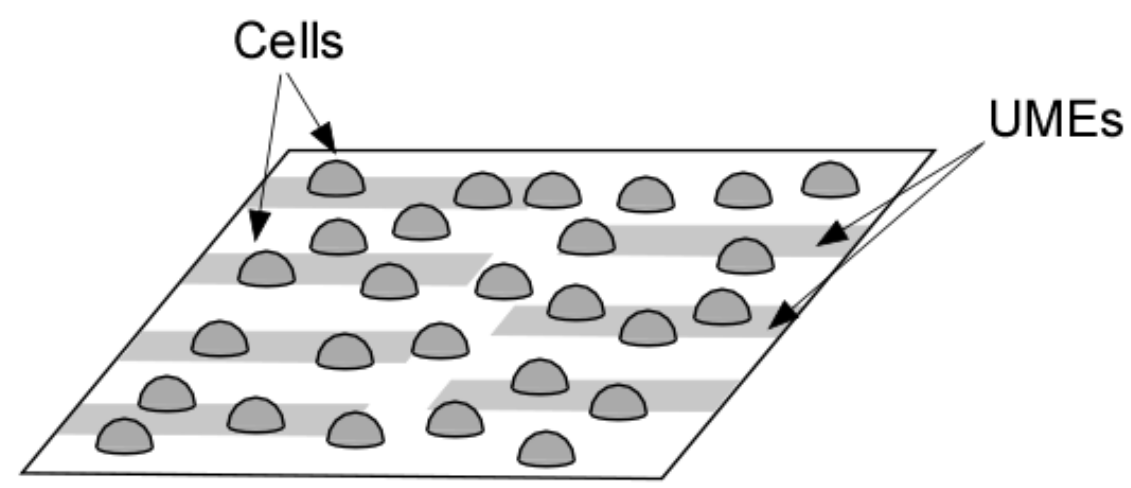

C)

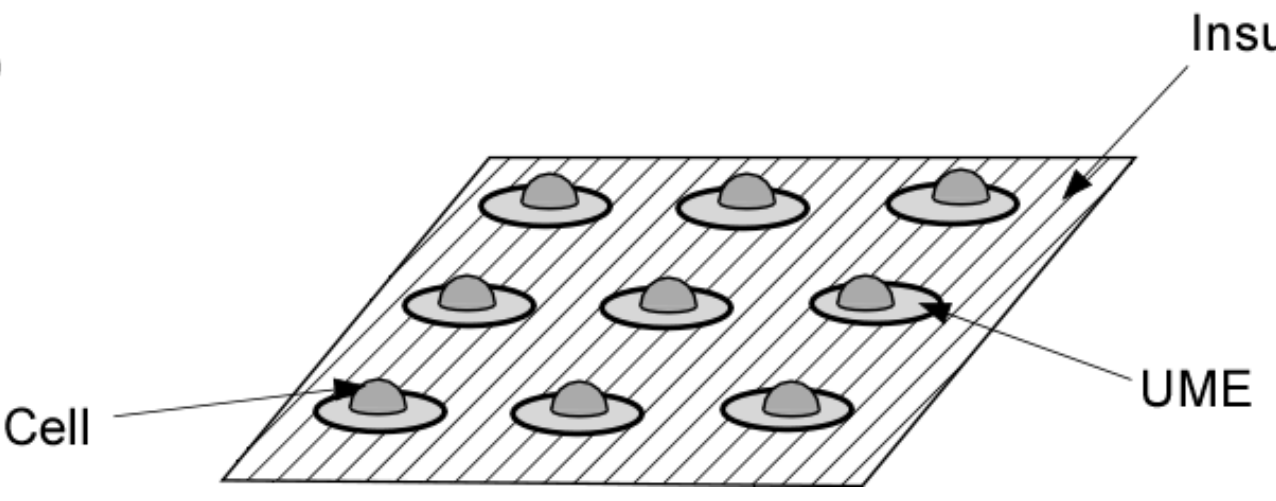


Figure 3.

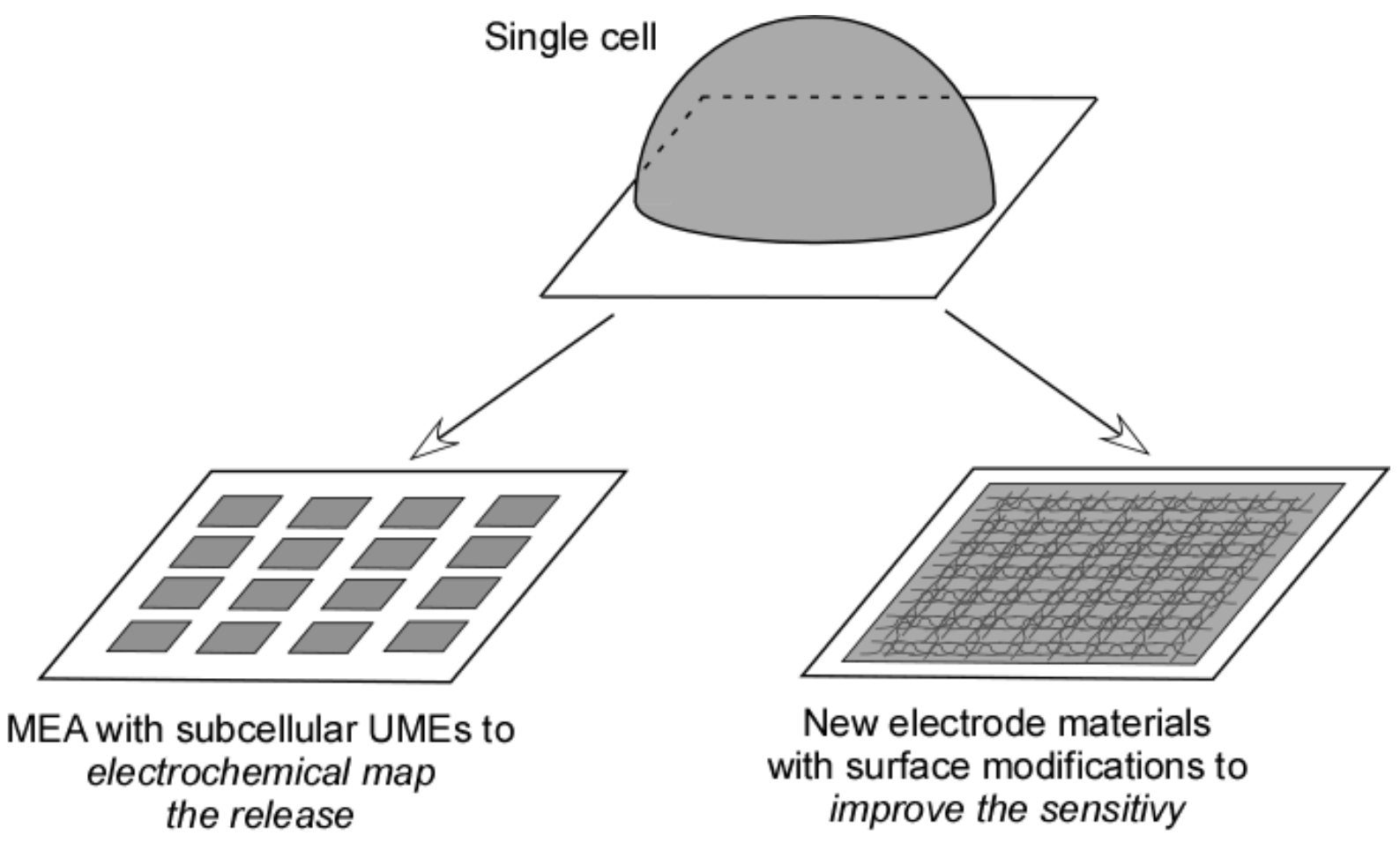


Figure 4.

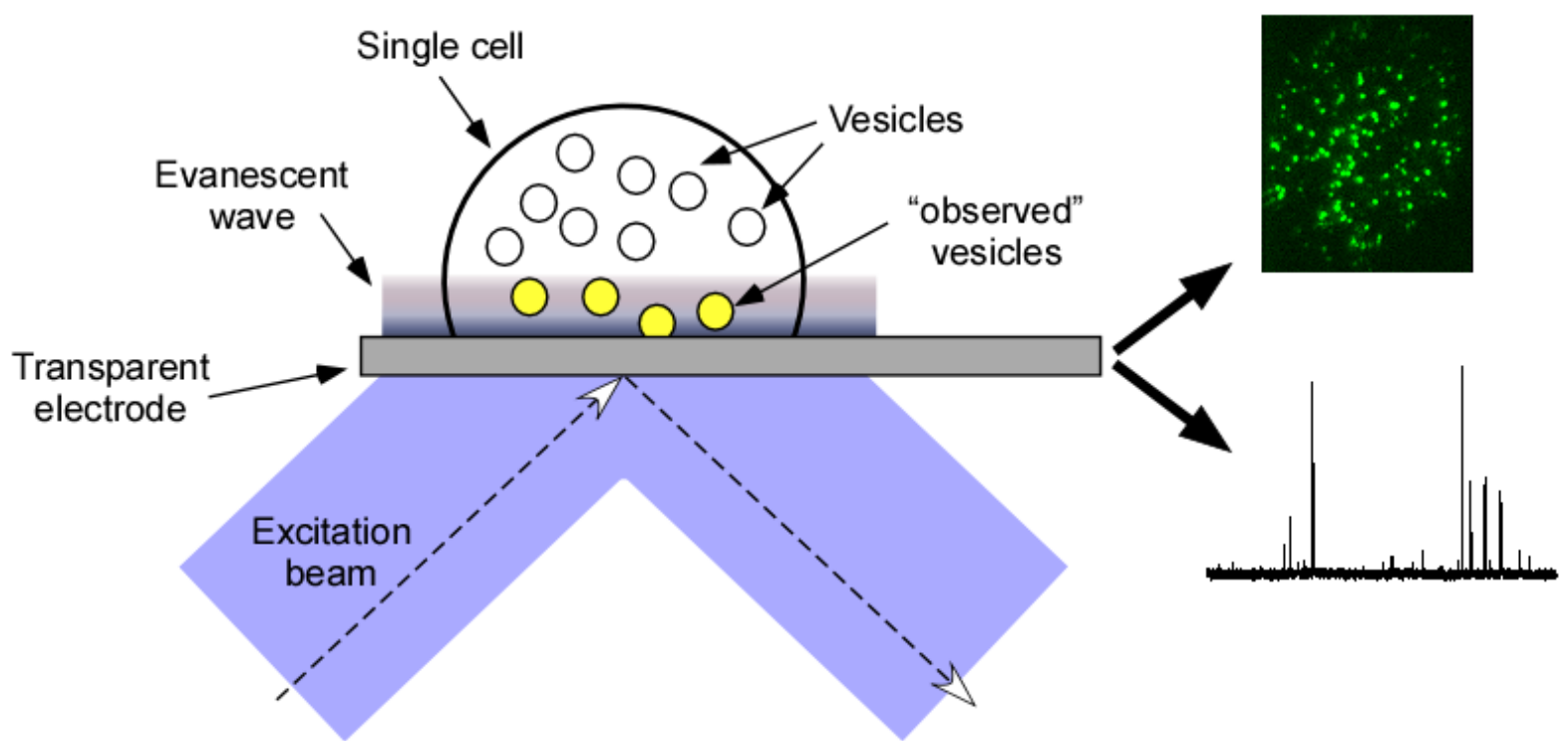




\section{Figure captions}

Figure 1. A) Main steps of vesicular exocytosis : (1) docking of the vesicles to the cell membrane by the mean of SNAREs assemblies (2) formation of a nanometric fusion pore (3) expansion of the fusion pore (4) possible full release . B) Scheme of the experimental configuration ("artificial synapse" configuration) involving electrochemical measurements (amperometry at constant potential). The carbon fiber ultramicroelectrode is positioned at the top of the emitting cell. The neurotransmitters released by exocytosis are oxidized at the electrode surface, thus leading to spikes of current as a function of time. Each spike corresponds to one individual vesicular release.

Figure 2. Schematic views of the main strategies for the investigation of cell population using MEAs. A) Within a microchannel. B) With a cell population randomly adhered on the MEA. C) With a cell population selectively adhered on the UMEs surfaces.

Figure 3. Two strategies related to single cell analysis with MEAs. Left: MEAs with subcellular UMEs dimensions should help to perform the electrochemical mapping of the cell release. Right: MEAs with electrode material other than carbon and with surface modifications (CNT...) for improving the electrode sensitivity.

Figure 4. Representative scheme of the fluorescence-amperometry combination which involves a transparent electrode. 


\section{REFERENCES}

1. R. D. Burgoyne and A. Morgan, Physiol. Rev., 2003, 83, 581-632 and references therein.

2. J. D. Keighron, A. G. Ewing and A. S. Cans, Analyst, 2012, 137, 1755-1763.

3. S. Ge, S. Koseoglu and C. L. Haynes, Anal. Bioanal. Chem., 2010, 397, 3281-3304.

4. R. Borges, M. Camacho and K. D. Gillis, Acta Physiol., 2008, 192, 173-184.

5. M. Lindau, Biochim. Biophys. Acta: General Subjects, 2012, 1820, 1234-1242.

6. C. Amatore, S. Arbault, M. Guille and F. Lemaitre, Chem. Rev., 2008, 108, 2585-2621.

7. C. Amatore, in Physical electrochemistry : principles, methods and applications., ed. I. Rubinstein, M. Dekker, New York, 1995, ch. 4, pp. 131-208.

8. H. F. Cui, J. S. Ye, Y. Chen, S. C. Chong, X. Liu, T. M. Lim and F. S. Sheu, Sensors Actuators B- Chem., 2006, 115, 634-641.

9. H.-F. Cui, J.-S. Ye, Y. Chen, S.-C. Chong and F.-S. Sheu, Anal. Chem., 2006, 78, 6347-6355.

10. L. Sasso, A. Heiskanen, F. Diazzi, M. Dimaki, J. Castillo-Leon, M. Vergani, E. Landini, R. Raiteri, G. Ferrari, M. Carminati, M. Sampietro, W. E. Svendsen and J. Emneus, Analyst, 2013, 138, 3651-3659.

11. M.-C. Chuang, H.-Y. Lai, J.-a. A. Ho and Y.-Y. Chen, Biosens. Bioelectron., 2013, 41, 602607.

12. A. Yakushenko, J. Schnitker and B. Wolfrum, Anal. Chem., 2012, 84, 4613-4617.

13. Y. F. Gao, X. H. Chen, S. Gupta, K. D. Gillis and S. Gangopadhyay, Biomed. Microdevices, 2008, 10, 623-629.

14. Y. F. Gao, S. Bhattacharya, X. H. Chen, S. Barizuddin, S. Gangopadhyay and K. D. Gillis, Lab Chip, 2009, 9, 3442-3446.

15. I. A. Ges, K. P. M. Currie and F. Baudenbacher, Biosens. Bioelectron., 2012, 34, 30-36.

16. C. L. Gao, X. H. Sun and K. D. Gillis, Biomed. Microdevices, 2013, 15, 445-451.

17. I. A. Ges, R. L. Brindley, K. P. M. Currie and F. J. Baudenbacher, Lab Chip, 2013, 13, 46634673. 
18. G. M. Dittami and R. D. Rabbitt, Lab Chip, 2010, 10, 30-35.

19. D. M. Omiatek, Y. Dong, M. L. Heien and A. G. Ewing, ACS Chem. Neurosci., 2010, 1, 234245.

20. B. Zhang, K. L. Adams, S. J. Luber, D. J. Eves, M. L. Heien and A. G. Ewing, Anal. Chem., 2008, 80, 1394-1400.

21. Y. Q. Lin, R. Trouillon, M. I. Svensson, J. D. Keighron, A. S. Cans and A. G. Ewing, Anal. Chem., 2012, 84, 2949-2954.

22. I. Hafez, K. Kisler, K. Berberian, G. Dernick, V. Valero, M. G. Yong, H. G. Craighead and M. Lindau, Proc. Natl. Acad. Sci. U. S. A., 2005, 102, 13879-13884.

23. S. Gosso, M. Turturici, C. Franchino, E. Colombo, A. Pasquarelli, E. Carbone and V. Carabelli, J. Physiol. (Lond.), 2014, 592, 3215-3230.

24. A. Pasquarelli, V. Carabelli, Y. Xu, E. Colombo, Z. Gao, J. Scharpf, E. Carbone and E. Kohn, Int. J. Environ. Anal. Chem., 2011, 91, 150-160.

25. J. Wang, R. Trouillon, Y. Q. Lin, M. I. Svensson and A. G. Ewing, Anal. Chem., 2013, 85, $5600-5608$.

26. J. Wang, R. Trouillon, J. Dunevall and A. G. Ewing, Anal. Chem., 2014, 86, 4515-4520.

27. S. Y. Yang, B. N. Kim, A. A. Zakhidov, P. G. Taylor, J. K. Lee, C. K. Ober, M. Lindau and G. G. Malliaras, Adv. Mater., 2011, 23, H184-H188.

28. H. G. Sudibya, J. M. Ma, X. C. Dong, S. Ng, L. J. Li, X. W. Liu and P. Chen, Angew. Chem. Int. Ed., 2009, 48, 2723-2726.

29. B. X. Shi, Y. Wang, K. Zhang, T. L. Lam and H. L. W. Chan, Biosens. Bioelectron., 2011, 26, 2917-2921.

30. B. Zhang, M. Heien, M. F. Santillo, L. Mellander and A. G. Ewing, Anal. Chem., 2011, 83, $571-577$.

31. K. Berberian, K. Kisler, Q. H. Fang and M. Lindau, Anal. Chem., 2009, 81, 8734-8740.

32. S. Barizuddin, X. Liu, J. C. Mathai, M. Hossain, K. D. Gillis and S. Gangopadhyay, ACS Chem. Neurosci., 2010, 1, 590-597. 
33. X. Liu, S. Barizuddin, W. Shin, C. J. Mathai, S. Gangopadhyay and K. D. Gillis, Anal. Chem., $2011,83,2445-2451$.

34. B. N. Kim, A. D. Herbst, S. J. Kim, B. A. Minch and M. Lindau, Biosens. Bioelectron., 2013, 41, 736-744.

35. L.-M. Li, W. Wang, S.-H. Zhang, S.-J. Chen, S.-S. Guo, O. Francais, J.-K. Cheng and W.-H. Huang, Anal. Chem., 2011, 83, 9524-9530.

36. A. Yakushenko, E. Katelhon and B. Wolfrum, Anal. Chem., 2013, 85, 5483-5490.

37. F. Lemaître, M. Guille-Collignon and C. Amatore, Electrochim. Acta, 2014, 140, 457-466.

38. B. X. Shi, Y. Wang, T. L. Lam, W. H. Huang, K. Zhang, Y. C. Leung and H. L. W. Chan, Biomicrofluidics, 2010, 4.

39. C. Amatore, S. Arbault, Y. Chen, C. Crozatier, F. Lemaître and Y. Verchier, Angew. Chem. Int. Ed., 2006, 45, 4000-4003.

40. A. Meunier, O. Jouannot, R. Fulcrand, I. Fanget, M. Bretou, E. Karatekin, S. Arbault, M. Guille, F. Darchen, F. Lemaître and C. Amatore, Angew. Chem. Int. Ed., 2011, 50, 5081-5084.

41. A. Meunier, M. Bretou, F. Darchen, M. G. Collignon, F. Lemaitre and C. Amatore, Electrochim. Acta, 2014, 126, 74-80.

42. A. Meunier, R. Fulcrand, F. Darchen, M. Guille Collignon, F. Lemaître and C. Amatore, Biophys. Chem., 2012, 162, 14-21.

43. K. Kisler, B. N. Kim, X. Liu, K. Berberian, Q. Fang, C. J. Mathai, S. Gangopadhyay, K. D. Gillis and M. Lindau, J. Biomater. Nanobiotechnol., 2012, 3, 243-253.

44. X. H. Sun and K. D. Gillis, Anal. Chem., 2006, 78, 2521-2525.

45. X. H. Chen, Y. F. Gao, M. Hossain, S. Gangopadhyay and K. D. Gillis, Lab Chip, 2008, 8, $161-169$.

46. V. Carabelli, S. Gosso, A. Marcantoni, Y. Xu, E. Colombo, Z. Gao, E. Vittone, E. Kohn, A. Pasquarelli and E. Carbone, Biosens. Bioelectron., 2010, 26, 92-98. 